\title{
Group Therapy in Adults with Obsessive-Compulsive Disorder: A Review
}

\author{
Sefa Bulut, Mustafa Subasi \\ Guidance and Counseling Psychology Department, Ibn Haldun University, Istanbul, Turkey \\ Email: sefa.bulut@ihu.edu.tr
}

How to cite this paper: Bulut, S. and Subasi, M. (2020) Group Therapy in Adults with Obsessive-Compulsive Disorder: A Review. Open Journal of Medical Psychology, 9, 150-159.

https://doi.org/10.4236/ojmp.2020.94012

Received: July 2, 2020

Accepted: September 24, 2020

Published: September 27, 2020

Copyright $\odot 2020$ by author(s) and Scientific Research Publishing Inc. This work is licensed under the Creative Commons Attribution International License (CC BY 4.0).

http://creativecommons.org/licenses/by/4.0/

(c) (i) Open Access

\begin{abstract}
In the treatment of OCD, several therapeutic approaches have been developed, including individual, group and/or pharmacological therapeutic methods. However, group therapy on OCD has received little research attention in comparison with other therapeutic methods and some studies demonstrated that OCD can be treated in group settings. In the literature, mentioned group therapies to treat OCD involve behavioral therapy, cognitive therapy, ERP (exposure and response prevention), cognitive behavioral therapy, ACT (acceptance and commitment therapy), supportive groups and individual therapy with family member involvement. In relation to their effectiveness, research indicated inconsistent findings. Therefore, the aim of this study was to address and to review whether group treatments on OCD are efficacious. This review focused on cognitive-behavioral group therapy (CBGT), $\mathrm{ERP}$, and ACT.
\end{abstract}

\section{Keywords}

Obsessive-Compulsive Disorder, Group Therapy, Cognitive-Behavioral Group Therapy, ACT, ERP

\section{Introduction}

OCD is defined as having obsessions and/or compulsions. Obsessions, which are persistent and iterative thoughts, impulses, or images, are experienced as intrusive, disturbing, uncontrollable, and undesirable. However, compulsions are repetitious behaviors or mental acts that an individual is driven to enforce due to an obsession or because of her/his own rules that s/he must rigidly apply or that must be strictly applied. Some other obsessive-compulsive and related disorders are featured by preoccupations. Some encompass recurrent body-focused repetitive behaviors (such as skin picking and hair pulling). Obsessive and compulsive 
symptoms frequently last one hour per day basis and cause significant distress and/or the person's or her/his family functioning is prevented [1]. OCD mainly consists of four symptom patterns that are contamination, pathological doubt, intrusive thoughts, and symmetry [2].

The disorder is a distressing and disabling condition for many individuals and includes recurrent obsessions that generally require compensation attempts through repeated and stereotypical compulsions (such as hand washing, checking things or putting them in order over and over or counting, praying, silently repeating certain words again and again). This behavior pattern often affects life quality in a negative way [3] and leads to a great deal of functional impairment [4]. It is usually a chronic condition which typically begins in adolescence and continues throughout life in general [5]. Affecting $2.5 \%$ of the general population, OCD is also the sixth most common psychiatric disorder [6] and is one of the top causes of disability related to illnesses worldwide [7]. Besides the lifetime prevalence in OCD among adults in the USA is nearly around 1\% to 3\% [8] and one study found that approximately more than $25 \%$ of people in the USA experience obsessions or compulsions at some point in their lives [6]. And if left untreated, it apparently leads to deterioration in social and vocational life [9]. Therefore, it should be treated to decrease the symptoms, to enhance the life quality of people and their well-being.

There are a number of therapeutic approaches that individually aim to treat OCD and its symptoms. Along with this, it is documented that OCD can also be treated by group therapy. OCD-related group therapies are mainly CBT followed by ERP and ACT - cognitive-behavioral approaches. However, group therapies on OCD have relatively received little attention and research indicated inconsistent findings. Thus, the need to address OCD group studies in order to describe the current literature regarding group OCD, to evaluate the advantages and disadvantages of the studies, to develop novel treatments, and to assess the effectiveness of the studies has emerged. In this review, it is aimed to evaluate OCD group treatments and to discuss their effectiveness and since cognitive-behavioral approach is the subject of most of the studies, the article focuses on it in particular as well as ERP and ACT.

\section{Literature Review}

Because of the fact that the disorder is a multifactorial disorder having various cognitive, emotional and behavioral dimensions, in the treatment of OCD, there are several therapeutic approaches that are approved to be effective in reducing obsessive-compulsive symptoms, to promote a better life and to decrease the rate of relapse. In this regard, among others especially pharmacotherapy, cognitive-behavioral therapy (CBT) and exposure response prevention (ERP) have been found to be effective to treat its symptoms in an array of studies [10]-[15].

Apart from individual practice data showing that the effectiveness of therapeutic methods on OCD, some studies demonstrated that OCD could be treated 
in group settings [16]-[28]. In the literature, mentioned group therapies involves behavioral therapy, cognitive therapy, ERP, and cognitive behavioral therapy combination, supportive groups, and individual therapy with family member involvement [20] [24] [29] [30]. Furthermore, ACT related group treatments can be added to the list above [31].

\subsection{Cognitive-Behavioral Therapy (CBT)}

Group therapy has its origins in psychodynamic models of psychopathology and developed before CBT. In group therapy, it is viewed that group members' interactions are the tool of change [32]. From the perspective of CBT, it is seen that individuals who have OCD inaccurately interpret situations, objects or thoughts being intrusive as hazardous. By way of cognitive and behavioral treatment strategies, CBT aims at changing/diminishing dysfunctional thoughts that produce anxiety and reducing/replacing behaviors that maintain symptoms [33] [34]. Some studies have proposed that cognitive therapy was an efficient alternative in many cases [35] [36].

In group-CBT, the cognitive-behavioral model given to the group is more than the interaction between the members. It is structured and directive, time-limited and collaborative as in individual CBT [30]. However, group-CBT pays also attention to the therapeutic factors occurring in therapy. Group-CBT encompasses:

1) cognitive restructuring through behavioral experiments,

2) normalizing through identification with others,

3) "in-vivo" exposure, positive reinforcement and vicarious learning in a safe environment,

4) the experience of mastery.

With respect to the effectiveness of CBT, there has been an array of studies. For example, Cabedo et al. [19] compared the efficacy of individual and group cognitive-behavior therapy for OCD treatment. They took into consideration the change in the severity of OCD in both the short and long term. Forty-two individuals having $O C D$ attended the treatment programs and were assigned to group CBT ( $\mathrm{n}=24$, in four groups) or to individual. Sixteen and twenty-two participants completed the treatments. The Y-BOCS were evaluated at pre- and post-treatment and at the one-year follow-up. At post-treatment the individual CBT treatment had higher recovered rate than group CBT and at follow-up the recovery rate decreased to $62.5 \%$ in individual CBT and to $31.8 \%$ in group CBT. That is, group CBT is effectively decreasing OCD symptoms and one year later the post-treatment changes remained unchanged. The finding that group OCD is less effective than individual CBT for OCD is supported by NICE [37].

Conversely, Çelik et al. [38] have reported that group CBT is decreasing the symptoms of obsessive-compulsive disorder in undergraduate students in Turkey. Along with this, in a 1-year follow-up study the results of CBGT were evaluated. The reduction in symptom severity observed at the end of the treatment 
was retained during one year. Eleven of forty-two patients relapsed in the follow-up term [39]. The CBGT's effectiveness is supported by this study but larger and long term-randomized controlled trials are necessary so as to validate this finding.

In a similar context, Haraguchi et al. [23] examined the influence of cognitive-behavioral group therapy (CBGT) on inflated responsibility. The aim of the study was to investigate the effect of CBGT on OCD and beliefs of responsibility. Thirty-six participants who meet the criteria of OCD in DSM-5 (Diagnostical and Statistical Manual of Mental Disorders) were recruited to the group and twenty-eight of them completed twelve sessions. Pre- and post-treatment evaluations were practiced. The results clearly documented that OCD symptoms and responsibility beliefs significantly improved at the end of the treatment. The study points out that CBGT improves both obsessive-compulsive symptoms and inflated responsibility beliefs in individuals who have OCD.

Regarding the severity of $\mathrm{CBT}$ and the effects on families, some researchers implemented a study to evaluate the impact of CBGT with the brief involvement of family members on family accommodation (FA) and to define predictors of FA reduction. 98 pairs of patients who have OCD and their family members were assessed. 52 were assigned to the intervention group (12 CBGT sessions) and 46 to a waiting list. FA and symptom severity were evaluated before and after the treatment. Significant improvement of OCD symptoms and FA scores was noted after the intervention in comparison to the control group. The predictors of family accommodation were the variables: patient features-absence of comorbid UPD (unipolar depression), lower obsession score, and higher education level; family member features-higher hoarding score. In the model, $47.2 \%$ of the variance was explained in FA scores after the treatment. So CBGT contributed to reducing FA for patients having OCD and the brief involvement of family members. These results can help CBGT protocols to be qualified [40].

Being in the spectrum of $\mathrm{OCD}$, hoarding disorder was also addressed in a study in terms of group-CBT without the clinicians' home visits. The participants having hoarding disorder engaged in either a 16 or 20 session program of group CBT and 30 (67\%) successfully completed treatment. The participants showed noteworthy improvements in hoarding symptoms as well as other symptoms such depression and anxiety. Their quality of life also increased after the treatment [41]. And the findings were comparable to two clinical trials on individual CBT which were published for the treatment of hoarding disorder [42] [43]. The results suggest that CBT group for hoarding disorder may be a cost-effective and practical therapeutic method.

Additionally, a study investigated the effectiveness of group-cognitive behavioral therapy versus SSRIs (fluoxetine) for obsessive-compulsive disorder. According to the conclusion, response rates to both treatments were congruent and lower than reported data in the literature. It may be because of the broad inclusion criteria and the resulting sample being more similar to the real setting [44]. 


\subsection{Exposure and Response Prevention (ERP)}

As well as CBT, ERP systemically and deliberately assists the person to get close his/her most feared thoughts or situations and refrain him/her from an activity which intentionally reduces anxiety [13]. Recently, ERP has grown into a valuable option of treatment. Exposure means exposing to stimulus that invokes fear and response prevention describes behavioral avoidance which relieves rituals, compulsions, and behaviors relevant to safety. In Foa and Kozak's meta-analysis [13], which encompasses 12 ERP studies and 330 OCD patients, it is reported that among patients there is an $83 \%$ response rate. However, ERP has high drop-out rates and low-level commitment.

In a pilot study, whether intensive ERP group treatment for OCD was effective was addressed. Six individuals whose OCD symptoms were basically different from each other engaged in the study and they had a long history of OCD, four having the disorder since childhood or early adolescence years. With prolonged exposure training on second and third day, the treatment which was designed as one long session, was conducted for four successive days. All of the patients stated high acceptance for the treatment format, content and protocols. When compared, there were 17.8 points reduction on Y-BOCS between pre- and post-treatment and at follow-up in six months the point just negatively increased 0.6 point [16]. This study implies that intensive group ERP seems to be a promising treatment for OCD and larger studies are also needed.

In a similar vein, Haland et al. [17] carried out a study about the effectiveness of ERP-focused group therapy for patients with OCD, which lasted 12 weeks in a community-based outpatient clinic in Norway. The participants involved 54 patients who have been diagnosed with OCD. The assessment scales were administered before treatment, after treatment and follow-ups ranging from 3 and 12 months. Analyses indicated that the offered group behavioral therapy to OCD patients dramatically improved ratings of OC symptoms along with depression and anxiety. The improvements were retained in both follow ups but the delayed effect of therapy wasn't observed after 12-month follow-up. The results point out that behavioral group therapy can be delivered to OCD patients as well as comorbid disorders. It can be concluded that this study supports the pilot study performed by Havnen et al. [16].

Another study examined if group-based CBT with ERP is efficient in patients who have OCD. The study involved twenty-four patients having OCD, they were divided into four groups and all participated in every session in group CBT which was designed to continue ten sessions. Each patient completed Y-BOCS and the Maudsley Obsessive-Compulsive Inventory (MOCI) at pre- and post-treatment. The YBOC mean (s.d.) score post-treatment was considerably lower than pre-treatment. But the study had some limitations. It was limited in sample size and the patients were not randomly assigned. Also, the researchers have not collected data on further management [45]. However, it can be gathered from the study that group therapy is a handy way of delivering CBT with 
ERP especially because of lower drop-out rates.

\subsection{Acceptance and Commitment Therapy (ACT)}

In one study conducted in Iran, the effects of adding group acceptance and commitment therapy (ACT) to individuals who have been diagnosed with obsessive-compulsive disorder (OCD) were investigated and they were already taking an optimal dose of SSRIs (selective serotonin reuptake inhibitors). The study was performed with forty-six Iranian women, on SSRIs, who were randomized to group ACT + SSRI or continued conditions. SSRI dosages were retained stable throughout the study. The results of the study showed considerable reductions on the Yale-Brown Obsessive-Compulsive Scale Self (Y-BOCS-SR) in both conditions at post-treatment. At follow-up, there were significant reductions in the ACT + SSRI condition when compared to only SSRI treatment. These results demonstrate that group ACT is a fruitful treatment for OCD and a successful alternative to SSRI treatment [31]. However, the study included some limitations that:

- the study was just confined to females,

- the sample size was small,

- there were just two months for follow-up to assess clinical outcomes,

- the study was implemented by self-reporting,

- random assignment and assessments were applied after all participants were on SSRIs.

\section{Conclusions}

OCD is a disabling and debilitating disorder and causes dysfunctionality in several domains of the person's life [1]. Various therapeutic models have been developed to treat OCD symptoms in a person-centered approach [10]-[15]. As well as individual therapies, group therapies are also practiced to effectively deliver mental health services to the patients having the disorder and to decrease OCD symptoms [16]-[28]. Group-CBT, being in the first place, and other group treatments, ERP and ACT, have been found to be efficient when compared to the individual practice, medical treatment, and waitlist. However, the literature has inconsistent findings about group effectiveness on CBT. This may be due to confounders consisting of symptom alienation, embarrassment of expressing obsessions/compulsions, comorbidity, sociodemographic conditions such as age, gender, race, ethnicity and so forth.

With all that, as discussed and addressed above, research point out that $\mathrm{CB}$ group treatments as well as ERP and ACT on OCD are a practicable and an alternative intervention to individual and medical treatment of OCD. Follow-up studies demonstrate that the effects of cognitive behavioral group treatments are maintained for some time. After all, cognitive-behavioral group treatments of OCD are a cost-effective and efficacious method to treat the symptoms of OCD and to enhance life-quality. ERP and/or ACT-based group treatment formats are 
also promising treatment options. Besides, larger studies and clinical trials are to be carried out. Further studies are required to compare the effectiveness of group treatment with individual therapy of OCD. Using a control group and other methodological ameliorations, additional researches are needed to validate the effectiveness of group treatments and to compare effect sizes related to them. Group and therapist(s) factors should also be considered and be evaluated in research processes.

\section{Conflicts of Interest}

The authors declare no conflicts of interest regarding the publication of this paper.

\section{References}

[1] American Psychiatric Association (2013) Diagnostic and Statistical Manual of Mental Disorders (DSM-5 ${ }^{\circledR}$ ). American Psychiatric Association Publishing, Washington DC. https://doi.org/10.1176/appi.books.9780890425596

[2] Sadock, B. and Ruiz, P. (2015) Kaplan \& Sadock's Synopsis of Psychiatry: Behavioral Sciences. Walters Kluwer, Alphen aan den Rijn.

[3] Cicek, E., Cicek, I.E., Kayhan, F., Uguz, F. and Kaya, N. (2013) Quality of Life, Family Burden and Associated Factors in Relatives with Obsessive-Compulsive Disorder. General Hospital Psychiatry, 35, 253-258. https://doi.org/10.1016/j.genhosppsych.2013.01.004

[4] Stein, D.J., Denys, D., Gloster, A.T., Hollander, E., Leckman, J.F., Rauch, S.L. and Phillips, K.A. (2009) Obsessive-Compulsive Disorder: Diagnostic and Treatment Issues. Psychiatric Clinics of North America., 32, 665-685. https://doi.org/10.1016/j.psc.2009.05.007

[5] Rasmussen, S.A. and Eisen, J.L. (1992) The Epidemiology and Clinical Features of Obsessive Compulsive Disorder. Psychiatric Clinics, 15, 743-758. https://doi.org/10.1016/S0193-953X(18)30205-3

[6] Ruscio, A.M., Stein, D.J., Chiu, W.T. and Kessler, R.C. (2010) The Epidemiology of Obsessive-Compulsive Disorder in the National Comorbidity Survey Replication. Molecular Psychiatry, 15, 53-63. https://doi.org/10.1038/mp.2008.94

[7] World Health Organization (1999) The "Newly Defined" Burden of Mental Problems. Geneva, WHO.

[8] Adam, Y., Meinlschmidt, G., Gloster, A.T. and Lieb, R. (2012) Obsessive-Compulsive Disorder in the Community: 12-Month Prevalence, Comorbidity and Impairment. Social Psychiatry and Psychiatric Epidemiology, 47, 339-349. https://doi.org/10.1007/s00127-010-0337-5

[9] Stein, D.J., Reghunandanan, S. and Fineberg, N. (2015) Obsessive-Compulsive and Related Disorders. Oxford Psychiatry Library, Oxford. https://doi.org/10.1093/med/9780198706878.001.0001

[10] Abramowitz, J.S. (1997) Effectiveness of Psychological and Pharmacological Treatments for Obsessive Compulsive Disorder: A Quantitative Review. Journal of Consulting and Clinical Psychology, 65, 44-52. https://doi.org/10.1037/0022-006X.65.1.44

[11] Eddy, K.T., Dutra, L., Bradley, R., et al. (2004) A Multidimensional Meta-Analysis of Psychotherapy and Pharmacotherapy for Obsessive-Compulsive Disorder. Clini- 
cal Psychology Review, 24, 1011-1030. https://doi.org/10.1016/j.cpr.2004.08.004

[12] National Collaborating Centre for Mental Health (2006) Obsessive-Compulsive Disorder: Core Interventions in the Treatment of Obsessive-Compulsive Disorder and Body Dysmorphic Disorder. National Clinical Practice Guideline; No. 31. British Psychological Society, Royal College of Psychiatrists, London.

[13] Kozak, M. and Foa, E.B. (1997) Mastery of Obsessive-Compulsive Disorder. Oxford University Press, New York. https://doi.org/10.1007/978-1-4899-1528-3_3

[14] Rosa-Alcázar, A.I., Sánchez-Meca, J., Gómez-Conesa, A. and Marín-Martínez, F. (2008) Psychological Treatment of Obsessive-Compulsive Disorder: A Meta-Analysis. Clinical Psychology Review, 28, 1310-1325. https://doi.org/10.1016/j.cpr.2008.07.001

[15] Van Balkom, A.J., Van Oppen, P., Vermeulen, A.W., Van Dyck, R., Nauta, M.C. and Vorst, H.C. (1994) A Meta-Analysis on the Treatment of Obsessive Compulsive Disorder: A Comparison of Antidepressants, Behavior, and Cognitive Therapy. Clinical Psychology Review, 14, 359-381. https://doi.org/10.1016/0272-7358(94)90033-7

[16] Havnen, A., Hansen, B., Haug, E.T., Prescott, P. and Kvale, G. (2013) Intensive Group Treatment of Obsessive-Compulsive Disorder: A Pilot Study. Clinical Neuropsychiatry, 10,48-55.

[17] Håland, Å.T., Vogel, P.A., Lie, B., Launes, G., Pripp, A.H. and Himle, J.A. (2010) Behavioural Group Therapy for Obsessive-Compulsive Disorder in Norway. An Open Community-Based Trial. Behaviour Research and Therapy, 48, 547-554. https://doi.org/10.1016/j.brat.2010.03.005

[18] Steele, A.L., Waite, S., Egan, S.J., Finnigan, J., Handley, A. and Wade, T.D. (2013) Psycho-Education and Group Cognitive-Behavioural Therapy for Clinical Perfectionism: A Case-Series Evaluation. Behavioural and Cognitive Psychotherapy, 41, 129-143. https://doi.org/10.1017/S1352465812000628

[19] Cabedo, E., Belloch, A., Carrió, C., Larsson, C., Fernández-Alvarez, H. and García, F. (2010) Group versus İndividual Cognitive Treatment for Obsessive-Compulsive Disorder: Changes in Severity at Post-Treatment and One-Year Follow-Up. Behavioural and Cognitive Psychotherapy, 38, 227-232. https://doi.org/10.1017/S135246580999066X

[20] Anderson, R.A. and Rees, C.S. (2007) Group versus İndividual Cognitivebehavioural Treatment for Obsessive-Compulsive Disorder: A Controlled Trial. Behaviour Research and Therapy, 45, 123-137. https://doi.org/10.1016/j.brat.2006.01.016

[21] Müller, A., Arikian, A., De Zwaan, M. and Mitchell, J.E. (2013) Cognitive-Behavioural Group Therapy versus Guided Self-Help for Compulsive Buying Disorder: A Preliminary Study. Clinical Psychology \& Psychotherapy, 20, 28-35. https://doi.org/10.1002/cpp.773

[22] Sousa, M.B., Isolan, L.R., Oliveira, R.R., Manfro, G.G. and Cordioli, A.V. (2006) A Randomized Clinical Trial of Cognitive-Behavioral Group Therapy and Sertraline in the Treatment of Obsessive-Compulsive Disorder. Journal of Clinical Psychiatry, 67, 1133-1139. https://doi.org/10.4088/JCP.v67n0717

[23] Haraguchi, T., Shimizu, E., Ogura, H., Fukami, G., Fujisaki, M. and Iyo, M. (2011) Alterations of Responsibility Beliefs Through Cognitive-Behavioural Group Therapy for Obsessive-Compulsive Disorder. Behavioural and Cognitive Psychotherapy, 39, 481-486. https://doi.org/10.1017/S1352465811000051

[24] Cordioli, A.V., Heldt, E., Bochi, D.B., et al. (2002) Cognitive-Behavioral Group 
Therapy in Obsessive-Compulsive Disorder: A Randomized Clinical Trial. Psychotherapy and Psychosomatics, 72, 211-216. https://doi.org/10.1159/000070785

[25] Jónsson, H., Hougaard, E. and Bennedsen, B.E. (2011) Randomized Comparative Study of Group versus İndividual Cognitive Behavioural Therapy for Obsessive Compulsive Disorder. Acta Psychiatrica Scandinavica, 123, 387-397. https://doi.org/10.1111/j.1600-0447.2010.01613.x

[26] Schwartze, D., Barkowski, S., Burlingame, G.M., Strauss, B. and Rosendahl, J. (2016) Efficacy of Group Psychotherapy for Obsessive-Compulsive Disorder: A Meta-Analysis of Randomized Controlled Trials. Journal of Obsessive-Compulsive and Related Disorders, 10, 49-61. https://doi.org/10.1016/j.jocrd.2016.05.001

[27] Behenck, A.S., Gomes, J.B. and Heldt, E. (2016) Patient Rating of Therapeutic Factors and Response to Cognitive-Behavioral Group Therapy in Patients with Obsessive-Compulsive Disorder. Issues in Mental Health Nursing, 37, 392-399. https://doi.org/10.3109/01612840.2016.1158335

[28] Şafak, Y., Karadere, M.E., Özdel, K., Özcan, T., Türkçapar, M.H., Kuru, E. and Yücens, B. (2013) Evaluation of the Effectiveness of Cognitive Behavioral Group Psychotherapy for Obsessive-Compulsive Disorder. Turk Psikiyatri Dergisi, 25, 1-8. https://doi.org/10.5080/u7510

[29] Jónsson, H. and Hougaard, E. (2009) Group Cognitive Behavioural Therapy for Obsessive-Compulsive Disorder: A Systematic Review and Meta-Analysis. Acta Psychiatrica Scand, 119, 98-106. https://doi.org/10.1111/j.1600-0447.2008.01270.x

[30] Bieling, P.J., Mccabe, R.E. and Antony, M.M. (2006) Cognitive Behavioral Therapy in Groups. Guilford Press, New York.

[31] Rohani, F., Rasouli-Azad, M., Twohig, M.P., Ghoreishi, F.S., Lee, E.B. and Akbari, H. (2018) Preliminary Test of Group Acceptance and Commitment Therapy on Obsessive-Compulsive Disorder for Patients on Optimal Dose of Selective Serotonin Reuptake İnhibitors. Journal of Obsessive-Compulsive and Related Disorders, 16, 8-13. https://www.sciencedirect.com/science/article/pii/S2211364917301719\# https://doi.org/10.1016/j.jocrd.2017.10.002

[32] Corey, G. (2011) Theory and Practice of Group Counseling. Nelson Education, Toronto.

[33] Rachman, S. (1997) A Cognitive Theory of Obsessions. Behaviour Research and Therapy, 35, 793-802. https://doi.org/10.1016/S0005-7967(97)00040-5

[34] Türkçapar, M.H. and Şafak, Y. (2012) Obsesif Kompulsif Bozuklukta Bilişsel Özellikler ve Bilişsel Tedaviler. Türkiye Klinikleri J Psychiatry-Special Topics, 5, 69-75.

[35] Cottraux, J., Note, I., Yao, S.N., et al. (2001) A randomized Controlled Trial of Cognitive Therapy versus Intensive Behavior Therapy in Obsessive-Compulsive Disorder. Psychotherapy and Psychosomatics, 70, 288-297. https://doi.org/10.1159/000056269

[36] Abramowitz, J.S. (1998) Does Cognitive-Behavioral Therapy Cure Obsessivecompulsive Disorder? A Meta-Analytic Evaluation of Clinical Significance. Behavioral Therapy, 29, 339-355. https://doi.org/10.1016/S0005-7894(98)80012-9

[37] National Institute for Clinical Excellence (NICE) (2006) Obsessive Compulsive Disorder: Full Guideline. http://www.nice.org.uk/guidance/CG31/guidance/pdf/English

[38] Çelik, S.B., Kumcağız, H. and Yılmaz, M. (2012) Grupla psikolojik danışmanın üniversite öğrencilerinin obsesif kompulsif belirti düzeyleri üzerine etkisi. Hacettepe 
Üniversitesi Eğitim Fakültesi Dergisi, 42, 121-130.

[39] Braga, D.T., Cordioli, A.V., Niederauer, K. and Manfro, G.G. (2005) Cognitive-Behavioral Group Therapy for Obsessive-Compulsive Disorder: A 1-Year Follow-Up. Acta Psychiatrica Scandinavica, 112, 180-186.

https://doi.org/10.1111/j.1600-0447.2005.00559.x

[40] Gomes, J.B., Cordioli, A.V., Bortoncello, C.F., Braga, D.T., Gonçalves, F. and Heldt, E. (2016) Impact of Cognitive-Behavioral Group Therapy for Obsessive-Compulsive Disorder on Family Accommodation: A Randomized Clinical Trial. Psychiatry Research, 246, 70-76. https://doi.org/10.1016/j.psychres.2016.09.019

[41] Gilliam, C.M., Norberg, M.M., Villavicencio, A., Morrison, S., Hannan, S.E. and Tolin, D.F. (2011) Group Cognitive-Behavioral Therapy for Hoarding Disorder: An Open Trial. Behaviour Research and Therapy, 49, 802-807.

https://doi.org/10.1016/j.brat.2011.08.008

[42] Tolin, D.F., Frost, R.O. and Steketee, G. (2007) An Open Trial of Cognitive-Behavioral Therapy for Compulsive Hoarding. Behaviour Research and Therapy, 45, 1461-1470. https://doi.org/10.1016/j.brat.2007.01.001

[43] Steketee, G., Frost, R.O., Tolin, D.F., Rasmussen, J. and Brown, T.A. (2010) Waitlist-Controlled Trial of Cognitive Behavior Therapy for Hoarding Disorder. Depression and Anxiety, 27, 476-484. https://doi.org/10.1002/da.20673

[44] Belotto-Silva, C., Diniz, J.B., Malavazzi, D.M., Valério, C., Fossaluza, V., Borcato, S., et al. (2012) Group Cognitive-Behavioral Therapy versus Selective Serotonin Reuptake İnhibitors for Obsessive-Compulsive Disorder: A Practical Clinical Trial. Journal of Anxiety Disorders, 26, 25-31. https://doi.org/10.1016/j.janxdis.2011.08.008

[45] Kearns, C., Tone, Y., Rush, G. and Lucey, J.V. (2010) Effectiveness of Group-Based Cognitive-Behavioural Therapy in Patients with Obsessive-Compulsive Disorder. The Psychiatrist, 34, 6-9. https://doi.org/10.1192/pb.bp.106.011510 